This month's Topical Review raises an extremely important question about the nature and causes of reading disability. The question centers on the role that specific features of English orthography play in reading difficulties. Does the way words are represented in the English alphabet present unique problems for children as they learn to translate between written and spoken language? In his attempt to answer this question, Stevenson discusses similarities and differences between English and non-alphabetic writing systems. Furthermore, he presents evidence that reading disabilities are no more common in America than they are in two Asian cultures that employ non-alphabetic systems.-JKT

\section{Orthography and Reading Disabilities}

\author{
Harold W. Stevenson, PhD
}

Recently, a number of influential writers have emphasized the role of orthography in the development of reading disabilities. The English writing system has been described by Gleitman and Rozin (1977), for example, as possessing "rampant irregularity, redundancy, and downright misrepresentation" (p. 35), while to these writers the Japanese writing system "seems ideal" (p. 36) from the point of utilizing scripts that represent both meanings and sounds. English, it is argued, poses problems for the beginning reader that are not encountered in learning to read the logographs (Chinese characters) and syllabary used in Japanese.

Could it be that the widespread incidence of reading disabilities in our culture can be traced in large part to the idiosyncracies of the spelling and writing system used in English? If this is true, what can be done to remedy the situation, other than following those who have proposed that the written form of English must be revised? The purpose of this article is to discuss these issues in the context of research dealing with writing systems and their relation to reading and reading disabilities.

\section{READING DISABILITIES IN CHINESE AND JAPANESE CHILDREN}

$\mathbf{R}$ eading disabilities are not seen as constituting a serious or frequent problem in the Orient. Such disabilities have received so little attention that neither in Chinese or Japanese is there a word or phrase that can be directly translated as "reading disability." It is not surprising, therefore, to find that many Japanese and Chinese authorities deny that reading disabilities exist, except in an extremely small proportion of the children in their countries.

Denial of such problems would have been unimpressive 30 years ago, when schooling was less common. But today nearly every child in places such as Japan, Taiwan, and Hong King is in primary school. (Statistics for school attendance in the People's Republic of China are not available.) It is very unlikely, therefore, that the reported lack of children with reading disabilities is due to selective attendance at school.

Possibly, the Chinese and Japanese fail to acknowledge that children may have reading disabilities. This suggestion was made by Critchley (1970), in his discussion of the lack of reading disability in Japan: "The most probable explanation is that in Japan, teachers, neurologists, and educational psychologists are not alive to the possible occurrence of dyslexia."

Makita (1974), a Japanese psychiatrist, argued that they were aware of the problem, and that they were searching diligently for dyslexic children. Makita continued:

While dyslexia, reading disability, reading difficulty, reading retardation, or whatever you prefer to call it, comprises a formidable portion of child psychiatric practice in western countries, its incidence in Japan is so rare that specialists in Japan do not get any referrals. In fact, none has been brought to this author since he started a children's psychiatric service in 1958 (p. 250).

Members of delegations to The Peo- ple's Republic of China have encountered a similar rejection of the notion that reading disabilities constitute a serious educational problem. Kline, (1977), for example, summarized his impressions in the following manner:

The teachers seemed puzzled by the idea that children could possibly have difficulty in learning to read. There was no evidence of learning disabilities and all of those with whom the question was raised denied that children there have dyslexia.

What appears to be the case, therefore, is that while the incidence of reading disabilities is generally estimated to include between $5 \%$ and $10 \%$ of the children enrolled in primary schools in the United States (with estimates in different locations varying from 3 to $30 \%$ ), few, if any Chinese and Japanese children are said to evidence such difficulties. This is a dramatic contrast, and one immediately seeks to discover factors that might lead to a better understanding of the genesis and remediation of the disabilities found in English-speaking children.

\section{ORTHOGRAPHY AND READING}

The major interpretation given to the reported lack of reading disabilities among Chinese and Japanese children relies upon the discussion of orthography. The Japanese syllabary provides greater consistencies between symbol and sound than does the English alphabet. Moreover, Chinese logographs, used in both Chinese and Japanese, offer greater possibilities for visual organization according to whole units than typically exists in the words of alphabetical languages such as English.

Martin (1973), for example, in an article, "Learning to read. Why Taro finds it easy but Johnny finds it hard," attributes differences in children's skill in reading Japanese and English to the orthographic systems used in these languages:

\footnotetext{
It appears to be true that what the human ear extracts from the speech signal is not, in the first instance, the phonemes or their components, but rather the syllables. And here is where Taro gets his big break. For the linguistic structure of Japanese is such that the syllable is virtually identical with the morphopho-
} 
neme, that is, with the phonetic units that make up the morphophonemes; moreover, the number of syllables in Japanese is quite small-no more than a hundred or so, even if we include a few odd types. It is an easy job for Taro to learn the kana syllabaries, because he immediately recognizes their linguistic basis in the syllable. In Johnny's case, the major hurdle seems to be breaking the syllable up into smaller entities.

Makita has written in a similar vein. In his well-known article published in the American Journal of Orthopsychiatry in 1968, he concluded his discussion in the following manner:

Theories which ascribe the etiology of reading disability to local cerebral abnormalities, to laterality conflict, or to emotional pressure may be valid for some instances, but the specificity of the used language, the very object of reading behavior is the most potent contributing factor in the formation of reading disability. Reading disability, then, is more of a philological than a neuropsychiatric problem (Makita, 1968, p. 613).

Finally, Liberman, Shankweiler, Fischer, and Carter $(1974, p .211)$, another widely quoted group, have described the orthographic hypothesis in the following way:

Since explicit phoneme segmentation is harder for the young child and develops later than syllable segmentation, one would expect that syllable- based writing systems would be easier to learn to read than those based on an alphabet. We may thus have an explanation for the assertion (Makita, 1968) that the Japanese kana, roughly a syllabary, is readily mastered by first-grade children. One might further expect that an orthography which represents each word with a different character (as is the case in Chinese logographs or in the closely related Japanese kanji) would also not cause the difficulties in initial learning that arise in mastering the alphabetic system. Indirect evidence of the special burden imposed by an alphabetic script can be found in the relative ease with which reading-disabled children learn kanjilike representations of language while being unable to break the alphabetic cipher.

One of the most extensive discussions of the relationship between orthography and reading is found in two long chapters by Gleitman and Rozin (1977) and Rozin and Gleitman (1977). They trace the history of writing systems and problems encountered in decoding each type of writing system. Alphabetic languages are claimed to embody the most complex writing systems because they involve the repetitive use of only a small number of abstract elements to represent the language. Chinese, on the other hand, is described as using a more concrete form of visual representation for words. Many symbols are required for writing Chinese, but because the symbols represent linguistically meaningful units, they are not considered to be as abstract as the letters of a phonetic spelling system. According to this line of reasoning, learning to read Chinese characters should depend strongly on memory, while learning to read English should depend upon the child's understanding of the relation of symbol to sound-a discovery difficult for some children. The basis of this difficulty has been hypothesized to lie in two general areas. First, a certain level of phonemic awareness is required in order to grasp the concept that speech can be segmented into phonemes and that these phonemes can be represented by symbols. Second, the system of rules that relates English to speech is difficult for the child to learn because it is both complex and irregular. Thus, while writing systems employing an alphabet are more efficient for fluent adults, it is proposed that they make greater conceptual demands on those beginning to learn to read the language.

\section{TEACHING READING DISABLED CHILDREN TO READ CHINESE CHARACTERS}

Much importance has been attached to a study by Rozin, Poritsky, and Sotsky (1971) by proponents of the preceding arguments. In this widely publicized study, success was reported in teaching children to read Chinese characters, even though the children were having serious difficulties in learning to read English. The study continues to be discussed. Crowder (1982), for example, reports that "Rozin, Poritsky, and Sotsky have shown that inner-city children with severe reading problems can easily learn to read English sentences with words represented as Chinese ideographs" (p. 224). Because of the importance given to this study as evidence for the influence of orthography on reading disability, it should be exam- ined more closely. Before doing this, however, a brief description of Chinese and Japanese may be of help to the reader who knows little about these writing systems.

\section{CHINESE}

Westerners have many mistaken notions about Chinese. Three of the most common are to consider the Chinese character as a pictograph (a picture script), as equivalent to a word, and as containing cues about meaning and pronunciation. Let us look at each of these misconceptions.

After thousands of years of modification and development, the Chinese writing system retains few examples of pictorial representations of concrete objects or actions. According to one authoritative estimate (Martin, 1972), only 5\% of all Chinese words are represented by simple pictographs or ideographs (semantic associates expressed by a pictograph), $5 \%$ are compound ideographs or phonetically represented foreign words, such as a foreign names, and $90 \%$ are phonetic compounds. The Chinese writing system can be best described, therefore, not as being a pictographic or ideographic writing system, but as a logographic system, one in which characters represent the minimal meaningful units of the language (morphemes).

Second, most words in Chinese are not represented by a single character. Meaning is generated by combining several characters to form a word, and the same character can have different meanings in different words. Writers such as Rozin and Gleitman (1977, p. 65) are simply incorrect when they write that there is a "massive difference in written-word knowledge between fluent English and Chinese readers . . . the average English high school student can read virtually every word he can utter and understand (around 50,000 items) . . . yet even Chinese scholars are estimated to know only about 4000 (characters)." Perhaps a better way to describe the situation is to consider that the reader who knows 4000 characters has available many thousands of roots which can be combined in different fashions to form tens of thousands of words. In all likelihood, there is little difference in the number of words that 
can be read by the literate Chinesespeaking and English-speaking adult.

We recently constructed a reading test in Chinese, English, and Japanese (Stevenson, Stigler, Lucker, Lee, Hsu, \& Kitamura, 1982). In order to do this, all words appearing in elementary textbook series currently used in Taiwan, Japan, and the United States were entered into a computer. When the words were counted, the total was approximately 7,000 for each writing system. During the first six years of elementary school, then, children were exposed to a reading vocabulary of about the same number of words in each of the languages.

A third misconception about the Chinese writing system is that each character can be broken down into parts, one consistently revealing information about pronunciation and the other consistently yielding information about the meaning of the character. This is correct for only a limited number of characters. Words written in Chinese characters cannot be decoded in such a regular fashion. As Tzeng, Hung, and Wang (1977) have argued, the relation between script and idea has become increasingly arbitrary with the development of the language.

This point can be illustrated with the character 品, which means letter. The left hand portion means person ("ren") and the right hand portion means word ("yen"). The pronunciation of the whole characer, however, is "xing." Moreover, the character also may mean honesty, believing, envoy, news, credentials, easy, and aimless. When the character is combined with other characters the meaning of the pair is even more varied; they can mean faith, envelope, trade wind, trust, signal, news, credit - and 34 other meanings (Liang, 1972). In reading words such as these, there seldom are cues about pronunciation from the components of the individual character, and only in some cases can we deduce from the combination of elements within or between characters what the pair might mean. learning one meaning for a single character is only the beginning. A much more complex, rich, and subtle set of meanings must be acquired in order to be a skilled reader of Chinese. In fact, the pronunciation and meaning of a character can be ascertained at times only by deduction from the context in which the character is embedded. Clearly, many descriptions of written Chinese appearing in Western textbooks on reading are vast oversimplifications of the writing system.

How are Chinese children taught to read? The approach used in teaching children differs, depending upon where the teaching occurs. In Taiwan, zhuyin fuhao, a phonetic spelling system is used to assist in the pronunciation of characters. Zhuyin fuhao is a set of $\mathbf{3}$ symbols for which there is consistent symbolsound (grapheme-phoneme) correspondence. The pronunciation of all Chinese characters can be represented by no more than three of these symbols. After 8-11 weeks, Chinese characters begin to be introduced. From then on the child faces the long-term task of learning and memorizing the meanings of the characters and their combinations. Several characters are learned each day, and through successive years children's reading vocabularies increase until they have acquired the approximately 3000 characters needed for reasonable literacy. Although initially the meaning of combinations of characters must be memorized, consistencies in their use often makes it easier to learn the meaning and pronunciation of other words employing one or more of these characters. For example, knowing the three characters for "American" (meiguo-ren) or "Chinese" (zhung-guo-ren) may aid the child in pronouncing the word "waiguoren" and in deducing that the characters for "wai" (outside) "guo" (country) "ren" (person) mean "foreigner."

Zhuyin fuhao notation continues to be printed alongside characters in the reading text for the first several years of elementary school in Taiwan. In the People's Republic of China the functions of zhuyin fuhao are assumed by pinyin, an alphabet with consistent graphemephoneme correspondence.

\section{JAPANESE}

Japanese children are first taught hiragana, a set of 46 symbols, each corresponding to a distinct syllable. The symbols are increased to 71 by the use of diacritic marks. For example, the kana for "ta" is transformed to "da" by the addition of a small superimposed double slash. All words in Japanese can be written with these 71 hiragana. Shortly after the hiragana are introduced, the children must begin to learn a second set of comparable symbols, katakana. Katakana are typically used in writing foreign words that have been introduced into the Japanese language. In addition, children are taught kanji, Chinese characters, which are used singly or in combinatin to represent words. Although whole sentences may be written solely in hiragana during the first months of school, kanji are rapidly introduced. By the end of the second half of the first grade the Japanese child is presented sentences that include all three forms of writing-hiragana, katakana, and kanji. By the end of middleschool all 1850 kanji that are considered to be necessary for the literate person have been presented, and sentences devoid of kanji are rare. As was the case with written Chinese, most descriptions of written Japanese greatly oversimplify the problems facing the young reader.

\section{The Rozin, Poritsky, and Sotsky study}

With this brief description of Chinese and Japanese, we can return to the study by Rozin et al. (1971). The children in this study were 8 inner-city, secondgrade children "with clear reading disability." The average level of reading skill in English was at a mid-first-grade level at the beginning of the study, and improved by nearly one-fourth year by the end of the study-that is, after the children had continued to attend regular classes and had received an average of 6.4 hours of tutoring in reading English. It is with some surprise, then, that these second-graders reading at beyond the first-grade level would have been considered to have reading disabilities.

More important for our purposes, however, is the conception of what Rozin et al. thought they taught the children. Training was broken down into seven stages; during each stage from two to six Chinese characters were presented. For example, in the first stage the characters represented mother, see, big, knife, has, and one. In the last stage they represented brother and black. A total of 30 characters were presented over an average of 4.4 hours of tutoring. From these characters sentences of the following form could be generated "Good brother not 
give man red car."

When the children were tested at the end of training on three stories, they made an average of only 6 errors in naming the 137 characters that appeared in the stories. (Obviously, many of the 30 characters appeared more than once.) Comprehension, however, was very low; an average of fewer than 2 of the 6 questions asked each child were answered correctly. The results were interpreted as supporting a view that "much reading disability can be accounted for in terms of the highly abstract nature of the phoneme (the critical unit of speech in alphabetic systems) and that an intermediate unit, such as the syllable, might well be used to introduce reading" ( $p .1264)$.

Upon close inspection this study turns out to be much less impressive as a demonstration of the role or orthography in reading than one might suspect from reading brief descriptions of the study in secondary sources. Rather than convincingly making the point that "disabled readers can acquire a logography with little difficulty even though its symbols are arbitrary and nonrepresentational," as Rozin and Gleitman (1977, p98) propose, the study appears to be nothing more than an illustration of a simple form of paired-associate learning.

Rote memory of the physical properties and the pronunciation of a character may be sufficient during the first days of learning to read. But as children continue to learn scores and then hundreds of characters, they are confronted with the complex, abstract nature of the Chinese writing system. The complexity of Chinese orthography was not evident when children were taught only 30 characters, when only single character-single word combinations were used, and when many of the sentences, as the authors suggest, were not "well formed." We are able to conclude nothing more from this study than that a group of 8 somewhat retarded readers were able to learn the names of 30 shapes.

There is little doubt that children are capable of paired-associate learning. There may be a question, however, whether children who have difficulty in segmenting the sounds contained in English words might not also have difficulty in reading words if they consisted at different times of one, two, or three characters appearing in different combinations, and when there is no indication in the string of characters appearing in a sentence when one word ends and another begins. We are left with no recommendations from this study that we can accept with confidence about appopriate methods for teaching reading or about the nature of reading problems.

\section{SPEECH RECODING IN READING CHINESE}

A study by Tzeng et al., (1977) provides evidence that phonemic recoding occurs in reading Chinese sentences. As was discussed above, Chinese characters contain little or no information about pronunciation. This does not mean, argue Tzeng et al., that characters are read without speech recoding or that it is common for meaning to be derived directly from the perceptual characteristics of the characters.

Two tasks were used in the study by Tzeng et al. In an interference task, four Chinese characters were presented, followed by six other characters representing words that contained the same beginning consonant, the same terminal vowel, or the same consonant and the same vowel as those in the first group of characters. (In the last case, of course, all characters had the same pronunciation as the original characters, and differed only according to one of four tones of Mandarin Chinese.) The original list was presented visually and the interference lists, aurally. In a test trial, the subjects, Chinese-speaking college students, were asked to recall the original characters. This procedure was repeated for 54 trials in a factorial design involving six trials of the nine combinations of training and interference lists. Strong interference effects appeared, especially when the pronunciation for the characters shared a common vowel or both a consonant and a vowel. Had the original characters been "read" solely according to meaning, there should have been little basis for a differential effect of the intervening materials upon their retention. The results are similar to those found in studies with English-reading subjects (Kintsch \& Buschke, 1969; Wickelgren, 1965).

A second task required the subjects to decide whether a string of Chinese char- acters constituted a normal or an anomolous sentence. In the anomolous sentences the verb was moved to a position impossible in Chinese. The normal sentences, written in Chinese characters, were of the following types: $\mathrm{Hu} / \mathrm{tu} \mathrm{fu} / \mathrm{fu}$ kan shu/mu. (The stupid husband and wife chopped down the trees.) and $\mathrm{Mi} / \mathrm{hu}$ fu/qi zai hua/cao. (The stupid husband and wife picked the flowers.) Phonemic similarity among the words represented by the characters significantly influenced the reaction time of the subjects in judging the grammaticality of both the normal and anomolous sentences. Again, if meaning were mapped directly onto the Chinese character without intervening speech recoding, similarity in the sounds of the words within a sentence should not have had a strong influence on reaction times.

These demonstrations suggest that orthographical factors may be a less important feature of reading than has been proposed. On the basis of this research and a review of many other studies investigating the role of writing systems in reading, Hung and Tzeng (1981) concluded that "comparisons of reading behaviors across different orthographies suggest that human visual information processing is indeed affected by orthographic variation, but only at the lower levels. With respect to the higher-level processing, reading behavior seems to be immune to orthographic variations" ( $p$ 377). Lower-level processing is considered to include such factors as visual scanning, perceptual demands, and cerebral lateralization functions. Higher-level processing, on the other hand, includes such processes as word recognition, working memory strategies, and comprehension. Hung and Tzeng conclude, as Gibson and Levin (1975) had concluded, and as Gray (1956) had concluded even earlier, that skilled readers of one orthographic system are able to read as efficiently as skilled readers of another system. (The reader interested in a comprehensive description of the literature on orthography and reading should consult the Hung and Tzeng review.)

If we accept this conclusion, it is hard then to accept the fact that Chinese and Japanese children do not show reading disabilities. English orthography should not be a critical factor in producing read- 
ing disabilities. We must ask, therefore, about the kinds of evidence that can be summoned to support statements such as Makita's about the failure to find children with reading disabilities in Asia.

\section{THE EVIDENCE CONCERNING LEARNING DISABILITIES}

A search for formal studies is fruitless. The evidence consists solely of informal observations or surveys made of teachers and other professionals. The studies tend to be of the type conducted by Kuo (1978), who asked elementary school teachers in Taiwan about the incidence of reading disabilities in their classrooms. On the basis of the results of his survey, Kuo concluded:

It was found that primary school teachers in Taiwan are unaware of the existence of such an issue. When the characteristics of reading disabilities were explained to them, they remarked that only a very limited number of their students fell into such a category of exceptionality" (p. 11).

Although the literature on learning to read English is voluminous, and there are numerous studies on learning to read Chinese and Japanese, no comparative studies involving Chinese, Japanese, and American children had been conducted until 1982 (Stevenson et al., 1982). Part of the reason for this lack of studies is that no instruments containing similar content and representing comparable levels of difficulty had been available in the three languages. Unless there are objective means of assessing reading level, it is impossible to determine whether the incidence of severe reading problems is greater or less among children reading one language than among children reading another.

\section{A STUDY OF READING DISABILITY AMONG CHINESE, JAPANESE, AND AMERICAN CHILDREN}

Our first task in undertaking a comparative study of reading disability was to devise a reading test. The reading test we constructed, and which was men- tioned above, was based upon a careful analysis of the vocabulary, grammar, and content of the reading texts used by elementary school children in Taiwan, Japan, and the United States. The test, individually administered to a child, yielded three scores: sight reading of vocabulary, reading of meaningful text material, and comprehension of text.

Children in the study included all the fifth-graders enrolled in 20 classrooms from 10 schools selected to be representative of elementary schools in Taipei, Taiwan; Sendai, Japan; and Minneapolis, Minnesota. We selected Minneapolis because it is a city with a low percentage of children from foreign-born and minority families. The other two cities were selected on the basis of their being the city in each country most similar to Minneapolis in terms of size, cultural and economic status. No mentally retarded children were included in our sample. The number of children from each city differed according to the number enrolled in the classrooms; 453 children were tested in Minneapolis, 956 in Taipei, and 775 in Sendai.

A problem common to all discussions of reading disability is what to accept as a definition of reading disability. A common definition is that the child not be mentally retarded or emotionally disturbed, but be behind in reading level by at least two years. This would mean that we should determine the percentage of children who were reading at below the third grade level. The percentages of children in Taiwan, Japan, and the United States who were unable to meet the criteria for success at the third-grade level (that is, who were reading at the secondgrade level) were $8 \%, 2 \%$, and $3 \%$, respectively. The severity of the problem is evident in the percentages of children who were unable to meet the criteria for success at the second grade level; the respective percentages were $2 \%, 1 \%$, and $5 \%$

A second common definition is that the child have low reading ability together with average or near-average IQ. We therefore determined the percentage of children from each city who were (a) in the lowest $10 \%$ of the distribution of reading scores within each city, and (b) obtained average scores higher than 1 standard deviation below the mean for both the verbal and performance items in a set of cognitive tasks. The percentages of children who met this criterion were $5.4 \%$ in Japan, $7.5 \%$ in Taiwan, and $6.3 \%$ in the United States.

Using these two common definitions of reading disability, it is obvious that there is no greater incidence of severe reading problems among children reading English than among those reading Chinese or Japanese. There is no support, therefore, for the belief that because of the orthographic systems of Chinese and Japanese, children reading those languages do not develop disabilities in reading.

Why should such the existence of such poor readers among elementary school children in Taiwan and Japan have eluded teachers, psychologists, and other professionals? There are several likely reasons. As indicated earlier, the topic elicited so little interest in the past that no Chinese or Japanese words were ever devised to represent the concept of severe reading problems or reading disability. It is very difficult to talk about a topic for which there is no word in the spoken language. Two more important factors were the absence of objective assessment instruments and the large numbers of children enrolled in Chinese and Japanese classrooms. No standardized reading tests have been available in Chinese, and only group tests have been published in Japanese. Teachers have relied primarily upon their own assessments, and when faced with classes containing an average of 35 to 50 children, diagnosis of the actual level of reading skill of individual children may be very difficult. Assessment of a child's reading level is further hindered in Asian classrooms because of the pervasive use of choral reading. Thus, teachers may not have appreciated the severity of some of the children's reading problems.

Perhaps most important of all, however, is the reluctance of Japanese and Chinese parents, teachers, and professionals to place children in categoriessomething that occurs much more readily in Western countries. Eastern philosophy emphasizes the malleability of the human being. Individuals are seen as differing from each other in their relative rates of development, rather than in the level of development they have attained. It is less 
likely, therefore, that poor performance would be recognized as a disability. Chinese and Japanese teachers surely recognize individual differences among the children in their classrooms. But slowness in reading would tend to be attributed to the child's lack of proper experience and poor motivation.

\section{CONCLUSIONS}

The information uncovered about the relation of orthography and reading is interesting and informative, but not very helpful in advancing our understanding of the genesis of reading disabilities. One thing seems clear: we cannot blame the alphabetic writing system used in English for the reading disabilities found among American children. No writing system appears to guarantee immunity from such problems. In attempting to represent the complex, abstract aspects of human languages as they have evolved over thousands of years, all writing systems necessarily turn out, in the end, to be complex, abstract, and not entirely consistent. Children face problems in learning to read these writing systems, whether the system involves learning to read different combinations of the letters of an alphabet, the thousands of characters of a logographic writing system, or the symbols found in a syllabary.

We are just beginning to gain an understanding of some of the factors that produce severe reading problems. The current tendency to view reading as a cognitive phenomenon, where the child operates as a seeker and processor of information, rather than as a perceiver and decoder of symbols, has begun to lead to some exciting new approaches to the understanding and remediation of severe reading problems. Reports of some of these are beginning to appear (e.g., Brown \& Palincsar, 1982). It is beyond the scope of the present article to discuss these studies, but they would be a useful focus for a later review. For now, however, we can put to rest the effort to understand reading disabilities in terms of the writing systems used in different languages. Although the form of writing used in any language may be an impediment to the efforts of certain children in learning to read, it seems very unlikely that any particular form of writing is especially conducive to the prodcution of severe reading problems.

\section{REFERENCES}

Brown, A. L., \& Palincsar, A. S. Inducing strategic learning from texts by means of informed, self-control training. Topics in learning and learning disabilities, 1982, 2, 1-17.

Critchley, M. The dyslexic child. London: Heinemann, 1970.

Crowder, $R$. G. The psychology of reading. New York: Oxford, 1982.

Gibson, E. J. \& Levin, H. The psychology of reading. Cambridge, Mass.: The MIT Press, 1975

Gleitman, L. R., \& Rozin, P. The structure and acquisition of reading $I$ : Relations between orthographies and the structure of language. In A. S. Reber \& D. L. Scarborough (Eds.), Towards a psychology of reading. Hillsdale, $N$. J.: Erlbaum, 1977.

Gray, W. S. The teaching of reading and writing. Chicago: Scott Foresman, 1956.

Hung, D. L., \& Tzeng, O. J. L. Orthographic variations and visual information processing. Psychological Bulletin, 1981, 90, 377-414.

Kintsch, W., \& Buschke, H. Homophones and synonyms in short-term memory. Journal of Experimental Psychology, 1969, 80, 403-407.

Kline, C. L. Development of dyslexia: An overview of transcultural factors. Paper presented at meetings of World Congress on Mental Health, Vancouver, B. C., August, 1977.

Kuo, W. F. A preliminary study of reading disability in the Republic of China. Collected papers, 1978, 20, 57-78. (National Taiwan Normal University)

Liang, S. C. A new practical Chinese-English dictionary. Taipei: Far East Book Co., 1972.

Liberman, I. Y., Shankweiler, D., Fischer, F. W., \& Carter, B. Explicit syllable and phenome seg. mentation in the young child. Journal of Experimental Child Psychology, 1974, 18, 201-212.

Makita, $K$. The rarity of reading disability in Jap- anese children. American Journal of Orthopsychiatry, 1968, 38, 599-614.

Makita, $K$. Reading disability and the writing sysetm. In J. E. Merritt (Ed.), New horizons in reading. Newark, Del.: IRA Press, 1974.

Martin, S. E. Nonalphabetic writing systems. In J. F. Kavanagh \& I. G. Mattingly (Eds.), Language by ear and by eye. The relationships between speech and reading. Cambridge, Mass.: MIT Press, 1972.

Martin, S. E. Learning to read: Why Taro finds it easy but Johnny finds it hard. Paper presented at Second Japan-U.S. Joint Sociolinguistic Conference, Tokyo, August, 1973.

Rozin, P., \& Gleitman, L. R. The structure and acquisition of reading II: The reading process and the acquisition of the alphabetic principle. In A. S. Reber \& D. L. Scarborough (Eds.), Toward a psychology of reading. Hillsdale, N. J.: Erlbaum, 1977

Rozin. P., Poritzsky, S., \& Sotsky, R. American children with reading problems can easily learn to read English represented in Chinese characters. Science, 1971, 171, 1264-1267.

Stevenson, H. W., Stigler, J. W., Lucker, G. W., Hsu, C. C., \& Kitamura, S. Reading disabilities The case of Chinese, Japanese, and English. Child Development, 1982, 53, 1164-1181.

Tzeng, O. J. L., Hung, D., \& Wang, W. S-Y. Speech recoding in reading Chinese characters. Journal of Experimental Psychology: Human Learning and Memory, 1977, 3, 621-630.

Wickelgren, W. A. Acoustic similarity and intrusion errors in short-term memory. Journal of Experimental Psychology, 1965, 70, 101-108.

\section{ACKNOWLEDGEMENT}

This paper was written while the author was a Fellow at the Center for Advanced Study in the Behavioral Sciences, supported by a fellowship from the John Simon Guggenheim Foundation and with additional support from the MacArthur Foundation. The author's research described in this article is supported by a grant from the National Institute of Mental Health (MH-30567).

\section{ABOUT THE AUTHOR:}

Harold W. Stevenson is a Professor in the Developmental Psychology Program at the University of Michigan. He is also a research fellow at the Center for Human Growth and Development in Ann Arbor, Michigan. He is widely known for his publications in the area of children's learning. Address: Department of Psychology, University of Michigan. Ann Arbor, Michigan, 42109. 